Article

\title{
Pathways to Attempted Suicide as Reflected in the Narratives of People with Lived Experience
}

\author{
Kätlin Luhaäär ${ }^{1}$ and Merike Sisask ${ }^{1,2, *(\mathbb{D})}$ \\ 1 School of Governance, Law and Society (SOGOLAS), Tallinn University, Narva mnt 25, 10120 Tallinn, \\ Estonia; katlin656@gmail.com \\ 2 Estonian-Swedish Mental Health and Suicidology Institute (ERSI), Õie 39, 11615 Tallinn, Estonia \\ * Correspondence: merike.sisask@tlu.ee or sisask.merike@gmail.com
}

Received: 20 March 2018; Accepted: 19 April 2018; Published: 20 April 2018

\begin{abstract}
Narratives, i.e., stories told by suicidal people, describing personal experiences and meanings given to these experiences, play an important role in understanding suicidal behaviour. The aim of the current study was to analyse suicidal processes that have resulted in attempted suicide and to improve the understanding of protective and risk factors of suicidal behaviour. Special emphasis was paid to religious/spiritual aspects. The material was collected in Estonia by conducting narrative interviews with adults (18 years or older) who had attempted suicide during their lifetimes $(\mathrm{N}=8)$. Thematic analysis was used for analysing the data. The main themes identified from the narratives were: childhood and family relationships, romantic relationships, alcohol/drug abuse, losses, sleep, previous suicide attempts, and religious/spiritual beliefs. The findings of the study show that there are many pathways to attempted suicide and that the process leading to attempted suicide is complex. Protective and risk factors are both multi-faceted.
\end{abstract}

Keywords: attempted suicide; narratives; protective factors; religious/spiritual aspects; risk factors; thematic analysis

\section{Introduction}

Suicide is a global major public health concern, with approximately 800,000 people dying by suicide each year. Additionally, for each suicide there are likely to be more than 20 people who have attempted suicide at least once (World Health Organization 2014). Epidemiological and sociological studies allow us to make generalizations about suicidal behaviours and influencing factors, but these statistical findings tell us little about the personal aspects of a suicidal act, which often remain unnoticed by the wider community and may not conform to general rules.

The spectrum of suicidal behaviours is wide, and due to the complicated nature of the phenomenon, it is difficult to define suicidal behaviour in a simple way. However, there is a consensus that suicidal behaviours comprise suicides (acts with a fatal outcome), attempted suicides (acts with non-fatal outcomes) and suicidal ideation (plans, thoughts), sometimes covered with the general term "suicidality" (Bertolote et al. 2005, 2009; De Gioannis and De Leo 2012; De Leo et al. 2006, 2004; Wasserman 2001a).

Suicide is understood as a process rather than an impulsive single act (Hawton et al. 1998; Wasserman 2001a, 2016c). This process starts with a mild and vague desire to die, which can fade away due to personal or interpersonal circumstances. Alternatively, it can develop further into suicidal ideation, and possibly culminate in a suicidal act-a suicide attempt or a suicide (Wasserman 2001a, 2016c). Hence, most suicide attempts are preceded by a process, in which dynamics are highly individual (Wasserman 2016c). The suicidal process can recur several times during a lifetime 
and is affected by various factors on the individual, interpersonal, and community levels, e.g., related to local culture and physical environment (Rimkeviciene et al. 2016; Wasserman 2001a).

In everyday life, people may have ongoing suicidal process without anyone noticing. They experience ambivalence about the desire to live or die (De Leo et al. 2004; Orbach 2001). To understand each person's unique perspective, it is important to listen and let people with lived experience of attempted suicide tell their stories-narratives-in a non-judgmental and trustful atmosphere (Littlewood et al. 2016; Michel et al. 2002, 2017; Muylaert et al. 2014; Orbach 2001).

Oxford Reference defines "lived experience" as "Personal knowledge about the world gained through direct, first-hand involvement in everyday events rather than through representations constructed by other people" (Oxford Reference 2018). We will never have direct access to the experience of another person, so we try to get as close as possible and rely on the speaker's testimony of his/her experience (Beuthin 2014). Nobody has been closer to actually dying by suicide than suicide attempters, which makes their narratives valuable for understanding the suicidal process. The core of the current article is an investigation of the lived experiences and different aspects of people's experiences, which will help to better understand the processes around suicide attempts.

All people have their own past experiences and "their own story". A situation that affects one person in one way does not necessarily affect another person similarly. It is an enigma why some individuals die by suicide or attempt suicide while others in a similar situation do not (Van Heeringen et al. 2004). Usually, there is an interplay of risk and protective factors; no single factor can explain a suicidal act (Ljušić et al. 2016; Wasserman 2001a).

The literature indicates that depression is one of the main risk factors for suicidal behaviour (Lönnqvist 2009). In case of depression, a person experiences despair, a feeling of inner emptiness, indifference and hopelessness (Cook and Borrill 2015; Wasserman 2001b). Some other psychiatric conditions-bipolar disorders, anxiety, eating disorders, adaptive disorders, schizophrenia and other psychoses-can also increase the risk of suicide (Lönnqvist 2009).

Many suicidal people's childhoods lacked parental care, proximity, warmth and understanding, and were instead full of negative emotions. This may result in negative feelings towards oneself and others and low self-esteem (Wasserman 2016b). Additionally, negative life events in childhood and in later life can have immense effects on people's vulnerable to suicide. Losses, changes, traumas-many people will experience such situations at some stage of life, but some may be affected in a way that leads to suicide (Dieserud et al. 2002; Kõlves et al. 2006; Wasserman 2016b, 2016a).

Although suicide is an individual decision, the social environment surrounding a person greatly influences it. The social environment includes family relationships, which are perhaps the most important, especially in childhood and adolescence. Family can provide either emotional security or have an adverse effect if close and trustful relationships are absent (Samm et al. 2010). Employment, migration and culture are also parts of the social environment potentially affecting people (Mäkinen and Wasserman 2001).

Protective factors, in contrast to risk factors, help vulnerable people cope with stress, thereby avoiding the development of the suicidal process. Protective factors include: good family relationships (with parents, children or other relatives), having a person in one's life who listens and provides help, a protected childhood where a child felt loved and needed, satisfying work and a healthy physical environment and lifestyle (food, exercise, daylight). Early recognition and treatment in case of mental illness is also a protective factor. (Wasserman 2001a).

One particularly interesting major cultural factor related to suicidal behaviour is religiosity/spirituality. Koenig et al. (2001) have described religion as an organized system of beliefs, practices, rituals and symbols designed to facilitate closeness to the sacred or transcendent. Religion is a wide and multifaceted concept in which many different dimensions can be distinguished, such as subjective religiosity. This is similar to the concept of spirituality, and is understood as a more informal and personally meaningful aspect than, for example, participation in a religious denomination 
or organizational religiosity (i.e., going to church or other place of worship) (Koenig et al. 2001; Sisask et al. 2010).

A review (Colucci and Martin 2008) found considerable evidence about the importance of spirituality (both religious and non-religious) in suicidal behaviours. According to Nelson et al. (2012), there is mounting evidence indicating that religion may serve as a protective factor against mental health problems, shielding individuals from the full weight of stressors encountered. Religion helps people cope with stress, and religious communities are supportive networks that provide practical and emotional support (Hayward et al. 2016). Mowat et al. (2008) claimed that most mainstream religious groups can provide protection against suicide. Different aspects of religiosity modified by cultural contexts have been shown to be protective factors against suicidal behaviour in several other studies (Moksony and Hegedús 2018; Sisask et al. 2010; Wu et al. 2015).

The Estonian context is particularly interesting for studying the role of religious/spiritual aspects in relation to suicidal behaviour. In Estonia, the suicide rate has been high, and despite a rapid decrease during the last two decades, it is still above the EU and global averages (Värnik et al. 2010; Värnik 2012; World Health Organization 2014). Estonia has been described as a very secular country, where less than one fifth of people officially report belonging to some denomination or claim that religion is important in their daily lives (Remmel and Uibu 2015; Ringvee 2014). At the same time, subjective religiosity in Estonia has been found to be a protective factor against attempted suicide (Sisask et al. 2010), and many Estonians believe in "something" related to spirituality and vitality. For Estonians, spirituality is a mix of their religious beliefs and practices that are suitable for modern individualized society (Remmel and Uibu 2015).

Alcohol and other substance abuse disorders are found in 25-50\% of all suicides (Ljušić et al. 2016). In the Estonian context, both alcohol abuse and alcohol dependence are important risk factors for suicide (Kõlves et al. 2006), as is also acute alcohol intoxication (Värnik et al. 2007). Substance abuse can lead to an accident, violence or suicide, because the ability to think or act rationally is decreased. Alcohol consumption influences adversely cognitive abilities and hence the ability to find alternative solutions. Impulsive behaviour while intoxicated increases the risk of suicide (Wasserman 2001c).

The aim of the current study is to investigate narratives of people who had attempted suicide during their lifetimes in order to analyse the suicidal process that has resulted in attempted suicide. To improve the understanding of protective and risk factors influencing suicidal behaviours, the authors used an exploratory research design that relies on in-depth interviews of people with lived experiences. Special emphasis was paid to religious/spiritual aspects.

\section{Method}

\subsection{Participants and Data Collection Procedure}

For the current study, 8 narrative interviews were conducted by one author (KL) from June to October 2017. Recruitment stopped when no new data were found in the narratives. KL has an educational background in law (BA) and is currently a master's student in social work. KL works as a negotiator at the Estonian Police and Border Guard Board and has received various trainings on how to approach vulnerable people and to talk about sensitive topics. The purposive sample included adults (aged 18+) who had attempted suicide during their lifetimes and volunteered to participate in the study. To find suitable participants, the authors co-operated with the Psychiatric Clinic of Pärnu Hospital (Estonia). The hospital staff made the first selection of participants of vulnerable people with acute mental health problems. People not confident in storytelling were not approached. All people approached and referred to participate in the study agreed to the narrative interview method. Study participants (interviewees) consisted of five females and three males, with an age range of 20-70. The research project was approved by the Tallinn Medical Research Ethics Committee (decision number 2162). 
Anonymity, confidentiality and informed consent are important ethical issues in qualitative studies (Sanjari et al. 2014). Before the interview started, the interviewer introduced the aims of the study and the interview procedure/conditions to the participant. The interviewee was asked to read and sign the informed consent form. The consent form contained contact details of the research team and detailed information about the study.

Interviews were conducted face-to-face at locations chosen by the interviewees to ensure comfort. The duration of interviews was 40-90 min. The interviews were digitally audio-recorded and transcribed by one author (KL). The transcripts were anonymized for data analysis; they were not returned to interviewees for comments and/or correction due to the sensitive topic (suicide). All interviewees were informed about the possibility of seeking psychiatric, psychological or crisis help from the Psychiatric Clinic of Pärnu Hospital if needed. All participants' data was treated confidentially, and the data was stored only on the author's computer (KL).

\subsection{Data Collection}

We used narrative interviews for data collection, which allowed us to get as close as possible to a personal story of a person with lived experience (Lindseth and Norberg 2004), in our case people with personal experience of attempted suicide. Researchers who use the narrative interview method do not set a specific procedure for the interview. Preferably, the interviewed person is allowed to guide the course of the conversation and the content; the interviewee chooses what to say and what not to say. However, the interviewer can ask leading questions if needed (Anderson and Kirkpatrick 2016).

The use of the narrative interview allows for the understanding of the personal and inter-personal experiences of one particular person. To accomplish that, it is the duty of the interviewer to be a good listener, and the interviewee is expected to be a good storyteller (Hollway and Jefferson 2000). Narrative interviews are used to give voice to specific groups of people who are often not heard-how they themselves understand their lives, the events of the past and future opportunities (Blustein et al. 2013).

\subsection{Data Analysis}

The methodological approach of the current study was interpretive social science (Neuman 2006), more specifically phenomenological hermeneutics (Lindseth and Norberg 2004) and social constructionism (Berger and Luckmann 1966). This methodological approach is an appropriate framework for qualitative research, in which the central goal is to create knowledge and improve understanding of subjective meanings and experiences of human beings, and also about the reality that is socially constructed in interactions between human beings.

While reporting the methods and results of the current study, the consolidated criteria for reporting qualitative studies (COREQ) was followed (Tong et al. 2007).

For data analysis, the thematic analysis method was applied (Braun et al. 2014; Braun and Clarke 2006). This method assists in discovering patterns in the collected data and making sense of them to fulfil the aims set for the study.

During the thematic analysis, the following six phases were completed (Braun and Clarke 2006). First, familiarizing with the transcribed data, reading and re-reading it carefully. Second, coding and generating initial codes across the entire data set. Third, searching for themes and collating codes into potential themes. Fourth, reviewing themes and checking if the potential themes identified in the third phase tell a convincing story; refining, splitting, combining or discarding some themes, if necessary. Fifth, defining and naming themes, refining the specifics of each theme and the overall story the analysis tells. Sixth, writing the manuscript, weaving together the overall story and illustrative quotations from the data, creating links with existing literature. Phases 1-3 were performed by one of the authors (KL); both authors (KL and MS) were involved in performing the phases 4-6. Involving the other author (MS) as a reviewer helped to build reliability in the thematic analysis coding conducted by the first author $(\mathrm{KL})$ and to test whether the themes identified were compatible with the whole text (Alhojailan 2012). 
In general, the thematic analysis was conducted in an inductive way using an open coding technique, in which coding and theme development are directed by the content of the data (Braun et al. 2014). There was one exception; as we were specifically interested in religious/spiritual aspects influencing the suicidal process, this theme was identified in advance. The respective codes were created, and the content of the data was assessed to identify specifically the presence or non-presence of religious/spiritual aspects across the entire data set.

As the analysis of the data collected with narrative interviews incorporates many perspectives of the experience, it allows for a more diverse and more credible picture of the subjects' experiences (Scârneci-Domnişoru 2013).

\section{Results}

This section outlines the process of reaching a suicidal crisis and the factors influencing the suicidal process. The results will be presented according to theme, and each theme is illustrated with supporting quotations from the interviews. The thematic analysis resulted in the following themes: childhood and family relationships, romantic relationships, alcohol/drug abuse, losses, sleep, previous suicide attempts, and religious/spiritual beliefs.

\subsection{Childhood and Family Relationships}

The most important theme was childhood and family relationships. Based on the narratives, a difficult childhood with complicated family relationships is a serious risk factor for attempted suicide. Complicated relationships with the mother implied difficulties with connectedness and an adverse childhood. This could mean continuous humiliation in childhood, ridiculing or feelings that the child is not good enough or is unwanted.

"I was like this black sheep in my family. Mother accused me for all the things, what I did at home or at school (pause) It's just that low self-esteem which I got from my family, this is the thing, which affects a lot." (Male, age 34)

The people interviewed revealed that poor relationships with their mothers have undermined their self-esteem. The lack of parental love in childhood has made them cling to people in adulthood to feel important to someone. When quarrels appear in adulthood, a memory of a similar childhood experience is triggered, leaving them feeling unwanted or superfluous.

"I haven't talked with my mother for years. I don't want to. (pause) She has shouted in my face several times in my life that she's sorry for giving birth to me and you know, that's the thing, that has affected me." (Male, 34)

Particularly bad relationships were also detected with the father/stepfather, some of whom were violent. The violence included hitting, humiliation and mocking.

"This suicide attempt was not from hating my father to show him, rather I was tired of everything and just wanted the situation to end. Continuous taunting and violence, I was tired of this and there was no hope for help. Our family was never visited by the police, my mother never called for help."

(Female, 45)

One of the interviewees had a stepfather who was violent towards the mother in front of the children. Another had a bad relationship with his father, which meant that the son did not seek advice from the father or contact him to discuss his worries.

"I felt the lack of a father. My father could have felt more concerned about me. We just could communicate better." (Male, 20)

One of the interviewees pointed out that as a child she attended a boarding school far away from her parents, and the situation did not allow her to see them often. She did not have a trustful 
relationship with her mother or father. In childhood, she felt she could only rely on herself, because her family was far away. Then in adulthood, she felt that she must manage everything by herself and that asking for help was disgraceful, making her look weak and unable to manage on her own.

"It is because it seemed to me all the time, why do you complain? That is my wrong understanding (pause) And another thing that I have been told is that I often do not ask for help and this is something I inherently know that if I can't manage, I do not admit it. This asking for help is something beyond me. I think if I say something then I am complaining. If I ask for help, I feel that I am failure or incapable and here I am perhaps just exaggerating." (Female, 47)

In the current study, the presence of family members was considered as an important protective factor: for example, mother, father, younger siblings and children. This is illustrated by a woman who suffered from physical and mental violence by her spouse for 13 years; by a young girl to whom her younger siblings were important; by a young man who never had a supportive family in his childhood.

"I wanted to kill myself. I went to the yard, even took a knife with me, but it was no use because I heard my children's voices all the time saying: "Mommy, Mommy". (Female, 34)

"I was holding the thought of my children, it kept me back." (Female, 34)

"If I no longer existed, it would hurt them very much. Thinking about my little brothers and sister (pause), I do not want them to remember only that they had a big sister once or something like this." (Female, 22)

"I have a dream, to have a decent family. To create this feeling of unity, I would like to be together with the family. This is probably something that I missed out in my childhood. I would like to accomplish this myself (pause) family is the most important and I am trying hard on it, I go to work. (pause) after this last attempt, quite a lot has changed in my head, I like to think more about it, about the future." (Male, 34)

Another quotation from the interview illustrates what has changed the individual's suicidal thoughts.

"My mother-in-law said that she will treat me as her own son and help me to get well (pause) Just having this support from someone is so important to me. It means also that someone likes, wants and helps me to get better and pushes me forward, but before I haven't had this (pause)." (Male, 34)

\subsection{Romantic Relationships}

An important theme in the narratives was romantic relationships. Interviewees indicated that one of the causes of their suicide attempts was difficulties in relationships.

"Then when the man was cheating and I got to know about it, it was such a feeling that (pause) but then you start to think clearly again." (Female, 49)

Specifically, the reasons were conflicts with a partner, a violent husband, misunderstandings with a girlfriend or boyfriend and humiliation by a boyfriend.

"So how do I live with such shame? That he hit me. There was no other chance at that moment,

I didn't even consider it." (Female, 49)

The narratives revealed that suicide attempts were made to save the relationship. They attempt to generate compassion in the other person and hold onto that person, in any way they can, so that they are not left behind. 
"I had constant conflicts with my partner (pause) yes (pause) in principle because of the relationship. To save the relationship. I jumped from the third floor, drunk. Well, maybe then (mumble/laugh) he would have started to love me. I do not know, something like that. But well, actually it tore us apart." (Male, 34)

Also, suicide attempts were made because relationships between people became unbearable due to humiliation, shame and violence. Sometimes such relationships can take an extreme form, but still remain as an untold story of a desperate and isolated person.

"He started checking my body for any signs and then he wanted to put a candle in my genital area. But as I refused, he pushed me down to bed and held me with one hand on my throat. And then he put it in anyway. It was painful (crying), but I could not ask for help because my phone was taken away to avoid any contact from my side, and then he tortured me for quite a while, until the kids came home." (Female, 34)

\subsection{Alcohol/drug Abuse}

Another observation was that the interviewees consumed alcohol before and during the suicide attempt. Less often, illicit drugs were involved in addition to alcohol.

"I think that a big contributor (pause) for what I did was drugs. I think that's why I lost my mind.

And then the same with alcohol (pause)." (Male, 20)

Narratives of the study revealed, how thoughts were snowballing and resulting in a suicide attempt.

"When I used drugs, all kinds of things went through my head and I overanalysed, actually it was not that bad, but you still overthink it (long pause)." (Male, 20)

Several participants in the study said they found courage in alcohol at the time of the suicide attempt.

"So alcohol is the main influencing factor concerning this suicide. But that's the thing with me,

I wouldn't dare to do such a thing when I am sober. I find courage in alcohol, always have." (Male, 34)

"I jumped from the third floor while drunk, as I had been drinking for a few days." (Male, 34)

All the interviewees who used alcohol at the time of the suicide attempt explained that it gave them courage.

"Finally, this amount of alcohol was so large that I no longer even doubted, but just wanted to jump."

(Female, 22)

"These bold thoughts come when I am drunk." (Male, 34)

\subsection{Losses}

In regards to "Losses", the death of a person close to the subject and ill health were also reported. In one case it was death of a child, but the death of a spouse and the death of a friend were also reflected in narratives.

"After the death of a child, this has had the most impact lately (pause) the baby died nearly 8 years ago, and during this 8 years I have not been looking for help anywhere. I have kept it in all the time."

(Male, 34)

"My friend died of cancer, after thinking about it, it could affect me too" (Female, 47) 
An elderly person had Parkinson's disease, which was the main reason for the suicide attempt, in addition to his wife's death. Since his wife's death 10 years ago, he has felt emptiness and loneliness. He had no one to talk to and no one to go out with. Additionally, the disease is worsening, and his physical movement is limited. These two losses are interconnected-death of the spouse and loss of health. This situation causes hopelessness, including fear of the future. He could not bear such a burden, and made two suicide attempts.

"Everything gets out of hand and you are not able to manage any more. I am only a burden and then yes, such stupid decisions were made." (Male, 70)

"The second time (pause) I woke up in the middle of the night and began to think that I would be a burden on others." (Male, 70)

\subsection{Sleep}

Interviewees experienced substantial sleep issues before the suicide attempt.

"And on all occasions I have had it in the same way. I lose my sleep." (Female, 47)

"In a word, first, the mood disappears (pause) then disappears, in a word, the appetite decreases gradually, and sleep gets worse until I do not sleep any more (pause) I know that in the last two weeks I did not sleep at all. (pause) You go to bed, but you're just lying down for seven or eight hours." (Female, 47)

With lack of sleep, people feel powerless and tired and begins to distance themselves from others. "Sleepiness and, in a word, my feeling is so poor that I just do not want to be any more. Physically poor." (Female, 47)

\subsection{Previous Suicide Attempts}

A prevalent theme in the narratives was "Previous suicide attempts". The people interviewed had attempted suicide more than once: in most cases two attempts, and one young man had three previous attempts. Surprisingly, all people with a history of previous suicide attempt(s) said that they did not tell anyone about their troubles before the attempt and did not seek help. Interviewees did not reveal their low mood or that they felt bad.

"And I start to hide it and I will not say anything, I pretend with a joyful voice and hide. I cannot make it, I do not want anyone to disturb me." (Female, 47)

"I'm such quite an introverted person, I do not want to talk about such things. So, I gather everything and then at some point I explode (pause)." (Male, 20)

Typically, the interviewees described their suicide attempts as a process where their thoughts got worse and worse.

"Day at a time, and (.) I can understand it all, but when those thoughts come to my head, they begin to deepen and deepen, and so long as you start acting once."

According to one narrative, there were three suicide attempts before the interview.

"Such a depression arises, a feeling of pressure. I can be so silent for weeks, well no (pause) I tell nothing (pause) and constantly I have one and the same image in my eyes. It's also like quite a depressing feeling. There is no way out from suicide. It's easier to treat yourself in the long run, if you start doing this again." (Male, 34)

When survivors of suicide attempts began to talk about their situations and suffering, they found it helpful as it relieved the tension. They needed a trigger to start talking and an opportunity to be heard.

"If I get help and I can talk, it helps a lot." (Female, 22) 


\subsection{Religious/Spiritual Aspects}

People telling their stories during the interviews had diverse perceptions of what religiosity/spirituality means and often they found it difficult to determine if these aspects influenced their lives or not. In one narrative of a middle-aged female, God was mentioned as a protective factor against suicidal behaviour.

"God, faith in Him. Of course there are hard times in life and if someone behaves badly and I quarrel with my husband and I face difficult moments in life, but when we both pray, then we find this common language and are able to solve everything. Prayers count and they are heard." (Female, 45)

She described her experience with great passion.

"I was thinking that if You, Jesus, are there, then come to my life. If I opened up to God, then I felt like all the crap that I had lived in before had been removed. I needed something real and pure, because I felt how dirty I was, considering the life I had lived. I remember that I cried uncontrollably, and I felt that my sins had been forgiven. A miracle happened that I began suddenly to understand the Bible." (Female, 45)

Apart from referring directly to God, several constructs referring to spiritual aspects were mentioned: faith in destiny, faith in nature.

"Instead, I believe in such things as nature. And I believe in previous lives, but I do not believe in God." (Female, 47)

"But yes, everything is for something or because of something. Everything at its own time or a little bit later, I still believe in such things, I do not think they are just spoken words. It's definitely the case that everything is for something and because of something. Let's say yes, I believe in destiny." (Female, 49)

One young man believed in life after death and in God (without mentioning God directly).

"I believe life after death. After death, there is still another life. (Confusion, long thought) After death, the soul stays on earth or something like that (laughter). I cannot tell you exactly, but I believe in such a thing, because the spirits still exist." (Male, 34)

"I have just not fulfilled my mission, it's perhaps also one reason why I have not succeeded. Still, there is someone who keeps or protects me." (Male, 34)

Because special attention within the current study was paid to the role of religion/spirituality in the suicidal process, the interviewer asked about people's beliefs, if the interviewees had not raised the topic.

"Do you have any belief in any of the higher powers that sustains you? Just as believers believe in God, do you have anything you believe in?" (interviewer)

However, frequently the interviewee did not understand the question about religiosity/spirituality. They had never thought about it and could not answer the question about the role religion or spirituality plays in their lives.

"This topic is far from me. I have nothing like that." (Female, 22)

"I cannot say (laughs). I have not even thought about such a thing, it's not a topic at all to me. The biggest support is by the family." (Male, 20)

"No, I cannot say that (pause) no (confused)." (Female, 34) 


\section{Discussion}

The current study focused on pathways to attempted suicide as reflected in the narratives of people with lived experience. The goal was to improve the understanding of protective and risk factors influencing suicidal behaviours. Special emphasis was paid to religious/spiritual aspects.

Themes related to childhood, family, and romantic relationships were the most important themes. Predominantly negative experiences and feelings from childhood and difficulties in relationships with immediate family members were described. Complicated relationships were experienced in childhood, especially with the mother, but also with the father or stepfather. These relationships often involved physical and/or psychological violence and neglect. These environments instil feelings of rejection and/or not being good enough for anything. Negative experiences from childhood poisoned relationships in later life.

It has long been known that negative emotions and events in childhood negatively affect self-esteem and the ability to trust, and cause tension between the super-ego and the ego. Freud's psychoanalytic theory, established at the beginning of the 20th century, indicates that childhood experiences have major influences on human behaviour in the future. According to Freud, the struggle between the super-ego and ego takes place, and the super-ego pushes the ego to suicide (Ronningstam et al. 2009).

Several studies have examined suicidal behaviours in conjunction with negative events in childhood and psychological/social problems in adulthood. Suicide is a long process that is affected by past events (Michel et al. 2002; Wasserman 2016c). Dieserud and colleagues 2002 found in their study on the association between negative childhood issues and suicide attempts that negative childhood events affected suicidal behaviours. If a child had been mistreated by his or her parents (mentally or physically), the probability of the child making a suicide attempt in the future is higher. Suicide attempters often come from broken homes or homes with insufficient parental care and violence (Wasserman 2001c, 2016a).

Good relationships between family members (or at least with one or some of them) were described as an important resource that helped participants to cope with stressful life-events, to survive intolerable situations and to create bright dreams for the future. Family members and especially children featured as protective factors: there was no desire to hurt them. Complicated and violent relationships were described as risk or acute triggering factors for attempted suicide.

According to an Austrian study, suicidal ideation, hopelessness and depression were higher among singles than among individuals in happy relationships, but lower than among those with low relationship satisfaction. Risk factors for suicide were higher among partners who reported unresolved conflicts with their partners, compared with those who rarely had conflicts or tended to solve their conflicts in a constructive manner. It was concluded that a well-functioning relationship can be a protective factor against suicidal behaviours (Till et al. 2016).

Joiner's interpersonal-psychological theory demonstrates how a psychosocial environment and relationships influence suicidal behaviours. According to this theory, three variables should be present for a person who will eventually die by suicide-a sense of frustrated belongingness, perceived burdensomeness and acquired capability for suicide. The first two variables generate the desire to die by suicide (psychosocial vulnerability) and the third variable enables the subject to reach the lethal suicidal act by acquired training of self-injury or witnessing/engaging in violence (e.g., in childhood or in an intimate relationship) (Anestis et al. 2009; Joiner 2005).

In the narratives, people described how their self-esteem was influenced by adverse relationships in childhood, during adolescence and in adulthood. They felt worthless and not good enough. Whatever others did, the subjects were not kind and forgiving towards themselves.

Along with the concept of self-esteem and its role in the suicidal process (Wasserman 2016c, 2016b), the concept of self-compassion has been described as an important issue affecting feelings and behaviours of vulnerable people (Neff 2003). According to (Neff 2003), self-compassion involves three basic components: (a) self-kindness-being kind and understanding to oneself rather than being 
self-critical; (b) common humanity—seeing one's experiences as a part of the larger human experience rather than in isolation; (c) mindfulness-being aware and balancing painful thoughts and feelings rather than over-identifying with them. Self-esteem is built on standards/norms established by the outside world; self-compassion means providing non-judgmental understanding of one's own pain, inadequacies and failures (Neff 2003). Self-compassion can mediate the influence of negative life-events and thereby reduce the risk of suicide (Chang et al. 2017).

Narratives brought up the role of alcohol and drugs in the suicidal process. These substances contributed to the process in two ways. First, alcohol/drug abuse contributed to the suicidal process in long run as separate risk factor, but also as an amplifier of other risk factors (e.g., worsened relationships). Second, consuming substances was also described as a factor that supported the final impulsive decision to attempt suicide by providing courage to take action. Hence, the use of alcohol and drugs intensified the suicidal process by excluding alternative solutions. A suicidal act is more likely to occur when a person is drunk and many problems have accumulated.

It is known from the literature that alcohol abuse exacerbates aggression and impulsive behaviour and can lead to suicidal behaviours (Wasserman 2001c; Yuodelis-Flores and Ries 2015). Therefore, alcohol and other substance abuse disorders as well as other patterns of alcohol misuse are important risk factors for suicide (Kõlves et al. 2006; Ljušić et al. 2016; Lönnqvist 2009; Värnik et al. 2007).

Another important theme that was related to relationships was "Losses". According to Orbach 2001, each suicide is associated with some loss: loss of a loved one, loss of work, loss of respect, etc. A person feels sorrow and fears about his/her losses and believes that there is no longer any meaning in the future and happiness can no longer be found.

The narratives of the current study revealed the following kind of losses: loss of a close person (death) and loss of health (incurable illness). Losses seem to have a major influence, especially on the lives of older people, who have been identified as the most vulnerable group for suicidal behaviours (Alves et al. 2014; Lapierre et al. 2011). This is largely due to loneliness (Alpass and Neville 2003). When a spouse is lost at an older age, it can often mean social isolation accompanied with depression. Suicide among older men who have lost their spouse is very common (Retterstøl and Mehlum 2001).

Death of an important person is a great loss, leaving a person with a feeling of emptiness. After the death of a spouse, the number of suicide attempts increased, rising more among men than among women. It is difficult for some people to change their everyday lives, and they may struggle to find a new goal or a new daily routine. The person feels that he or she is not needed anymore, which can increase the risk of suicide (Wasserman 2016a).

Most of the studies about associations between depression and suicidal behaviours emphasize that depression is one of the most important risk factors, with both cognitive and emotional aspects (Cook and Borrill 2015; Lönnqvist 2009; Wasserman 2001a). Interestingly, depression did not emerge as a separate theme in the current study. It can be hypothesized that depression as a clinical concept and diagnosis does not have an important meaning for ordinary people, because they use different "language". Professionals (clinicians, researchers) use different ways of thinking and different words that are not necessarily similar to how patients think and talk about their health issues (Toomela 2005). However, even if depression was not a separate theme, depressive feelings were mentioned under other themes like "Sleep" and "Previous suicide attempts". It seems like these themes are more meaningful for interviewees and better related to their personal experiences than the clinical term "depression".

People with sleep problems have a higher risk of suicide. There is some evidence about the relationship between sleep and suicidal behaviour, but some authors state that this relationship needs further investigation. A study involving people with suicidal thoughts or with a history of attempted suicide revealed that at night, when everything is quiet, it is difficult to keep from having negative thoughts (Littlewood et al. 2016). Another study found that problems with falling asleep and excessive sleeping may be associated with an increased risk of depression. Moreover, sleep medications, 
short sleep duration (less than $6 \mathrm{~h}$ ) and sleep disorders are signs of suicide risk (Gunnell et al. 2013; Sarchiapone et al. 2014).

Sleepiness involves tiredness and withdrawal from others, which exacerbates negative thinking. Sleeping well means that people can manage everyday life, but if sufficient sleep is not achieved, life can become more difficult (Littlewood et al. 2016). One study concluded that suicide attempts could be reduced by treating sleep disorders. Disturbed sleep is what can be easily treated and improved by medication (Krakow et al. 2011).

People who have had suicide attempts in the past have the greatest risk of making another suicide attempt. Previous suicide attempts are also the most important risk factors for suicide (Gysin-Maillart et al. 2016; Roelands et al. 2017). The risk increases with each subsequent suicide attempt and remains high for over 30 years. The MONSUE study found that the risk of repetition within the year after inclusion in the study was higher for those who had previous suicide attempts, and the risk increased with the number of previous suicide attempts (Burón et al. 2016). People with recurrent suicide attempts experience great ambivalence about dying or living, and they would rather survive from moment to moment (Bergmans et al. 2017). About $90 \%$ of the people who have attempted suicide will survive; therefore, a suicide attempt is definitely one reason to look for professional help to resolve problems (Retterstøl and Mehlum 2001). However, a major barrier to effective treatment is poor treatment compliance; $50 \%$ of people fail to participate in treatment because patients often feel that they are not understood (Gysin-Maillart et al. 2016).

Although a person can live with a partner, the person can be emotionally alone and not share his/her feelings with anyone. The interviewees in the current study seldom shared their feelings and concerns with anyone prior to a suicide attempt. They rarely sought any help and didn't use the help provided. In later reflections, they realized that sharing and talking about their worries can help to better understand and to find other solutions.

This study paid special attention to the role of religion/spirituality in the suicidal process. The results showed that most of the people telling their stories distanced themselves from religion and they did not consider it as a protective factor. Additionally, when the interviewer asked about people's beliefs (if the topic did not emerge by itself), the question was not understood or the interviewee was confused as he or she had never thought about it. The God as the central concept of religion was mentioned in only one narrative. Some interviewees talked about other aspects of spirituality such as faith in destiny, faith in nature and belief in life after death. Without asking, the theme of religious/spiritual aspects would not be reflected in most of the narratives.

As described in the introduction, religion (and spirituality) is a wide and multifaceted concept (Koenig et al. 2001). In a very secular country (Estonia) there is a confusion about what role religion/spirituality has in people's lives and how to define it (Remmel and Uibu 2015; Ringvee 2014). This remains an interesting topic for further research.

Importantly, none of the risk factors discussed above occurred in the narratives in isolation. No single problem led to a suicide attempt. The reasons were interconnected and interact with each other, leading to a point at which a person does not want to live anymore. Interviewees described this as a process in which everything accumulates. The interviewees experienced suicide as a process during which suicidal thoughts amplify until they culminate in an act, where the main goal is death. People understand that this process is underway, but they are unable to ask or search for help, and many people do not know where the help might be available.

The current study has several limitations. Firstly, as has been pointed out by Hollway and Jefferson (2000), some memories may cause a lot of anxiety and are therefore either forgotten or suppressed, and have likely been changed or modified over time. Secondly, the study is based on a relatively small purposive sample. However, data saturation was one of the criteria considered in the decision to stop collecting the qualitative data. Thirdly, the narrative interview presumes that individuals have some basic abilities in storytelling. There are those who are less verbal or who do not like to share their experiences and are therefore less likely to participate in a narrative 
study. Fourthly, as the subject of suicide in general is sensitive and stigmatized, people may feel uncomfortable participating in such a study.

Still, the current study contributes to the knowledge about suicidal behaviours and related protective and risk factors by providing insight into a profound personal experience-the course of approaching an attempted suicide. This study looks at what is meaningful in the suicidal process for people with personal experience in attempted suicide. In our study we adopted an holistic approach and looked at various aspects of the suicidal experience, rather than exploring a single aspect in isolation. The study findings provide valuable clues for clinicians and further research.

Acknowledgments: This work was supported by the Estonian Research Council (grant PRG71). The authors are grateful to the Psychiatric Clinic of Pärnu Hospital (headed by Raine Pilli) for helping to find participants for the study and to the participants for sharing their stories.

Author Contributions: K.L. and M.S. developed the concept of the study. K.L. conducted the narrative interviews, transcribed the data, generated initial codes, and searched for potential themes. K.L. and M.S. both reviewed and checked themes if themes gave a convincing story, defined and named themes refining the specifics of each theme. K.L. and M.S. wrote the manuscript, weaving together the overall story with illustrative quotations from the data, and creating links with existing literature. Both authors discussed the results and approved to the final version of the manuscript.

Conflicts of Interest: The authors declared no conflicts of interest.

\section{References}

Alhojailan, Mohammed Ibrahim. 2012. Thematic analysis: A critical review of its process and evaluation. West East Journal of Social Sciences 1: 39-47.

Alpass, Fiona M., and Stephen Neville. 2003. Loneliness, health and depression in older males. Aging and Mental Health 7: 212-16. [CrossRef] [PubMed]

Alves, Verônica de Medeiros, Ana Claudia C. Maia, and Antonio Egidio Nardi. 2014. Suicide among elderly: A systematic review. MedicalExpress 1: 9-13. [CrossRef]

Anderson, Claire, and Susan Kirkpatrick. 2016. Narrative interviewing. International Journal of Clinical Pharmacy 38: 631-34. [CrossRef] [PubMed]

Anestis, Michael, Craig Bryan, Michelle Cornette, and Thomas Joiner. 2009. Understanding suicidal behavior in the military: An evaluation of joiner's interpersonal-psychological theory of suicidal behavior in two case studies of active duty post-deployers. Journal of Mental Health Counseling 31: 60-75. [CrossRef]

Berger, Peter L., and Thomas Luckmann. 1966. The Social Construction of Reality: A Treatise in the Sociology of Knowledge. London: Penguin Books.

Bergmans, Yvonne, Evelyn Gordon, and Rahel Eynan. 2017. Surviving moment to moment: The experience of living in a state of ambivalence for those with recurrent suicide attempts. Psychology and Psychotherapy: Theory, Research and Practice 90: 633-48. [CrossRef] [PubMed]

Bertolote, José M., Alexandra Fleischmann, Diego De Leo, Jafar Bolhari, Neury Botega, Damani De Silva, Huong Tran Thi Thanh, Michael Robert Phillips, Lourens Schlebusch, Airi Värnik, and et al. 2005. Suicide attempts, plans, and ideation in culturally diverse sites: The WHO SUPRE-MISS community survey. Psychological Medicine 35: 1457-65. [CrossRef] [PubMed]

Bertolote, J., Danuta Wasserman, and C. Wasserman. 2009. Development of definitions of suicidal behaviours: From suicidal thoughts to completed suicides. In Oxford Textbook of Suicidology and Suicide Prevention: A Global Perspective. Edited by Wasserman Danuta and Camilla Wasserman. Oxford: Oxford University Press, pp. 87-90.

Beuthin, Rosanne E. 2014. Breathing in the Mud: Tensions in Narrative Interviewing. International Journal of Qualitative Methods 13: 122-34. [CrossRef]

Blustein, David L., Saliha Kozan, and Alice Connors-Kellgren. 2013. Unemployment and underemployment: A narrative analysis about loss. Journal of Vocational Behavior 82: 256-65. [CrossRef]

Braun, Virginia, Victoria Clarke, and Nicola Rance. 2014. How to use thematic analysis with interview data (process research). In The Counselling \& Psychotherapy Research Handbook. Edited by Vossler Andreas and Naomi Moller. London: Sage. Available online: http://www.uk.sagepub.com/textbooks/Book239261 (accessed on 5 March 2018). 
Braun, Virginia, and Victoria Clarke. 2006. Using thematic analysis in psychology. Qualitative Research in Psychology 3: 77-71. [CrossRef]

Burón, P., Luis Jimenez-Trevino, P. A. Saiz, M. P. García-Portilla, P. Corcoran, V. Carli, Sandor Fekete, G. Hadlaczky, U. Hegerl, K. Michel, and et al. 2016. Reasons for Attempted Suicide in Europe: Prevalence, Associated Factors, and Risk of Repetition. Archives of Suicide Research 20: 45-58. [CrossRef] [PubMed]

Chang, Edward C., Tina Yu, Alexandria S.-M. Najarian, Kaitlin M. Wright, Wenting Chen, Olivia D. Chang, Yifeng Du, and Jameson K. Hirsch. 2017. Understanding the association between negative life events and suicidal risk in college students: Examining self-compassion as a potential mediator. Journal of Clinical Psychology 73: 745-55. [CrossRef] [PubMed]

Colucci, Erminia, and Graham Martin. 2008. Religion and spirituality along the suicidal path. Suicide $\mathcal{E}$ Life-Threatening Behavior 38: 229-44. [CrossRef]

Cook, Lisa C., and Jo Borrill. 2015. Identifying suicide risk in a metropolitan probation trust: Risk factors and staff decision making. Legal and Criminological Psychology 20: 255-66. [CrossRef]

De Gioannis, Angelo, and Diego De Leo. 2012. Managing suicidal patients in clinical practice. Open Journal of Psychiatry 2: 49-60. [CrossRef]

De Leo, Diego, Shelly Burgis, José Manoel Bertolote, Ad JFM Kerkhof, and Unni Bille-Brahe. 2006. Definitions of suicidal behavior: Lessons learned from the WHo/EURO multicentre Study. Crisis 27: 4-15. [CrossRef] [PubMed]

De Leo, Diego, Shelley Burgis, José M. Bertolote, A. J. F. M. Kerkhof, and Unni Bille-Brahe. 2004. Definitions of suicidal behaviour. In Suicidal Behaviour: Theories and Research Findings. Edited by DeLeo Diego, Unni Bille-Brahe, Ad Kerkhof and Armin Schmidtke. Gottingen: Hogrefe \& Huber, pp. 17-39.

Dieserud, Gudrun, Lisa Forsén, Marc T. Braverman, and Espen Røysamb. 2002. Negative Life Events in Childhood, Psychological Problems and Suicide Attempts in Adulthood: A Matched Case-Control Study. Archives of Suicide Research 6: 291-98. [CrossRef]

Gunnell, David, Shu-Sen Chang, Min Kuang Tsai, Chwen Keng Tsao, and Chi Pang Wen. 2013. Sleep and suicide: An analysis of a cohort of 394,000 Taiwanese adults. Social Psychiatry and Psychiatric Epidemiology 48: 1457-65. [CrossRef] [PubMed]

Gysin-Maillart, Anja, Simon Schwab, Leila Soravia, Millie Megert, and Konrad Michel. 2016. A Novel Brief Therapy for Patients Who Attempt Suicide: A 24-months Follow-Up Randomized Controlled Study of the Attempted Suicide Short Intervention Program (ASSIP). PLoS Medicine 13: e1001968. [CrossRef] [PubMed]

Hawton, K., Ella Arensman, Danuta Wasserman, A. Hulten, Unni Bille-Brahe, T. Bjerke, P. Crepet, E. Deisenhammer, A. Kerkhof, D. De Leo, and et al. 1998. Relation between attempted suicide and suicide rates among young people in Europe. Journal of Epidemiology \& Community Health 52: 191-94. [CrossRef]

Hayward, R. David, Neal Krause, Gail Ironson, Peter C. Hill, and Robert Emmons. 2016. Health and Well-Being Among the Non-religious: Atheists, Agnostics, and No Preference Compared with Religious Group Members. Journal of Religion and Health 55: 1024-37. [CrossRef] [PubMed]

Hollway, Wendy, and Tony Jefferson. 2000. Researching Defended Subjects with the Free Association Narrative Interview Method. London: Sage.

Joiner, Thomas. 2005. Why People Die by Suicide. Cambridge: Harvard University Press.

Koenig, Harold G., Michael McCullough, and David B. Larson. 2001. Handbook of Religion and Health. Oxford: Oxford University Press.

Kõlves, Kairi, Airi Värnik, Barbara Schneider, Jürgen Fritze, and Jüri Allik. 2006. Recent life events and suicide: A case-control study in Tallinn and Frankfurt. Social Science \& Medicine 62: 2887-96. [CrossRef]

Kõlves, Kairi, Airi Värnik, Liina-Mai Tooding, and Danuta Wasserman. 2006. The role of alcohol in suicide: A case-control psychological autopsy study. Psychological Medicine 36: 923-30. [CrossRef] [PubMed]

Krakow, Barry, Jessica D. Ribeiro, Victor A. Ulibarri, Jessica Krakow, and Thomas E. Joiner. 2011. Sleep disturbances and suicidal ideation in sleep medical center patients. Journal of Affective Disorders 131: 422-27. [CrossRef] [PubMed]

Lapierre, Sylvie, Annette Erlangsen, Margda Waern, Diego De Leo, Hirofumi Oyama, Paolo Scocco, Joseph Gallo, Katalin Szanto, Yeates Conwell, Brian Draper, and et al. 2011. A Systematic Review of Elderly Suicide Prevention Programs. Crisis 32: 88-98. [CrossRef] [PubMed]

Lindseth, Anders, and Astrid Norberg. 2004. A phenomenological hermeneutical method for researching lived experience. Scandinavian Journal of Caring Sciences 18: 145-53. [CrossRef] [PubMed] 
Littlewood, Donna L., Patricia Gooding, Simon D. Kyle, Daniel Pratt, and Sarah Peters. 2016. Understanding the role of sleep in suicide risk: Qualitative interview study. BMJ Open 6: e012113. [CrossRef] [PubMed]

Ljušić, Dragana, Dragan Ravanić, Snežana Filipović-Danić, Ivan Soldatovic, Jovana Cvetković, and Mirjana Stojanović-Tasić. 2016. Contemporary principles of suicide prevention. Medicinski Pregled 69: 367-71. [CrossRef]

Lönnqvist, Jouko. 2009. Major psychitric disorders in suicide and suicide attempters. In Oxford Textbook of Suicidology and Suicide Prevention: A Global Perspective. Edited by Wasserman Danuta and Camilla Wasserman. Oxford: Oxford University Press, pp. 275-86.

Mäkinen, Ilka Henrik, and Danuta Wasserman. 2001. Some social dimensions of suicide. In Suicide: An Unnecessary Death. London: Martin Dunitz, pp. 101-8.

Michel, Konrad, John T. Maltsberger, David A. Jobes, Antoon A. Leenaars, Israel Orbach, Kathrin Stadler, Pascal Dey, Richard A. Young, and Ladislav Valach. 2002. Discovering the truth in attempted suicide. American Journal of Psychotherapy 56: 424-37. [PubMed]

Michel, Konrad, Ladislav Valach, and Anja Gysin-Maillart. 2017. A Novel Therapy for People Who Attempt Suicide and Why We Need New Models of Suicide. International Journal of Environmental Research and Public Health 14: 243. [CrossRef]

Moksony, Ferenc, and Rita Hegedûs. 2018. Religion and Suicide: How Culture Modifies the Effect of Social Integration. Archives of Suicide Research, 1-12. [CrossRef] [PubMed]

Mowat, Harriet, John Swinton, C. Stark, and D. Mowat. 2008. Religion and Suicide: Exploring the Role of the Church in Deaths by Suicide in Highland, Scotland. Aberdeen: Mowat Research Ltd. Available online: https://www.abdn.ac.uk/sdhp/content-images/Religion_and_Suicide_exploring_the_role_of_ the_church_in_deaths_by_suicide_in_Highland_Scotland.pdf (accessed on 5 March 2018).

Muylaert, Camila Junqueira, Vicente Sarubbi, Jr., Paulo Rogério Gallo, Modesto Leite Rolim Neto, and Alberto Olavo Advincula Reis. 2014. Narrative interviews: An important resource in qualitative research. Revista Da Escola De Enfermagem Da USP 48: 184-89. [CrossRef] [PubMed]

Neff, Kristin. 2003. Self-Compassion: An Alternative Conceptualization of a Healthy Attitude toward Oneself. Self and Identity 2: 85-101. [CrossRef]

Nelson, Graham, Ryan Hanna, Alaa Houri, and Bonnie Klimes-Dougan. 2012. Protective functions of religious traditions for suicide risk. Suicidology Online 3: 59-71.

Neuman, W. Lawrence. 2006. Social Research Methods: Qualitative and Quantitative Approaches, 6th ed. Boston: Allyn and Bacon.

Orbach, Israel. 2001. How Would You Listen to the Person on the Roof? A Response to H. Omer and A. Elitzur. Suicide and Life-Threatening Behavior 31: 140-43. [CrossRef]

Oxford Reference. 2018. Available online: http://www.oxfordreference.com/view/10.1093/oi/authority. 20110803100109997 (accessed on 8 March 2018).

Remmel, Atko, and Marko Uibu. 2015. Outside Conventional Forms: Religion and Non-Religion in Estonia. Religion and Society in Central and Eastern Europe 8: 5-20. [CrossRef]

Retterstøl, N., and L. Mehlum. 2001. Attempted suicide as a risk factor for suicide: Treatment and follow-up. In Suicide: An Unnecessary Death. Edited by Wasserman Danuta. London: Martin Dunitz, pp. 125-31.

Rimkeviciene, Jurgita, John O'Gorman, and Diego De Leo. 2016. How do clinicians and suicide attempters understand suicide attempt impulsivity? A qualitative study. Death Studies 40: 139-46. [CrossRef] [PubMed]

Ringvee, Ringo. 2014. Religion: Not declining but changing. What do the population censuses and surveys say about religion in Estonia? Religion 44: 502-15. [CrossRef]

Roelands, Marc, Reginald Deschepper, and Johan Bilsen. 2017. Psychiatric Consultation and Referral of Persons Who Have Attempted Suicide. Crisis 38: 261-68. [CrossRef] [PubMed]

Ronningstam, Elsa, Igor Weinberg, and John T Maltsberger. 2009. Psychoanalytic theories of suicide. Historical overview and empirical evidenc. In Oxford Textbook of Suicidology and Suicide Prevention: A Global Perspective. Edited by Wasserman Danuta and Camilla Wasserman. Oxford: Oxford University Press, pp. 149-58.

Samm, Algi, Liina-Mai Tooding, Merike Sisask, Kairi Kõlves, Katrin Aasvee, and Airi Värnik. 2010. Suicidal thoughts and depressive feelings amongst Estonian schoolchildren: Effect of family relationship and family structure. European Child \& Adolescent Psychiatry 19: 457-68. 
Sanjari, Mahnaz, Fatemeh Bahramnezhad, Fatemeh Khoshnava Fomani, Mahnaz Shoghi, and Mohammad Ali Cheraghi. 2014. Ethical challenges of researchers in qualitative studies: The necessity to develop a specific guideline. Journal of Medical Ethics and History of Medicine 7: 1-6.

Sarchiapone, Marco, Laura Mandelli, Vladimir Carli, Miriam Iosue, Camilla Wasserman, Gergö Hadlaczky, Christina W. Hoven, Alan Apter, Judit Balazs, Julio Bobes, and et al. 2014. Hours of sleep in adolescents and its association with anxiety, emotional concerns, and suicidal ideation. Sleep Medicine 15: 248-54. [CrossRef] [PubMed]

Scârneci-Domnişoru, Florentina. 2013. Narrative technique of interviewing. Bulletin of the Transilvania University of Brasov 6: 21-28.

Sisask, Merike, Airi Värnik, Kairi K[otilde]lves, José M. Bertolote, Jafar Bolhari, Neury J. Botega, Alexandra Fleischmann, Lakshmi Vijayakumar, and Danuta Wasserman. 2010. Is Religiosity a Protective Factor Against Attempted Suicide: A Cross-Cultural Case-Control Study. Archives of Suicide Research 14: 44-55. [CrossRef] [PubMed]

Till, Benedikt, Ulrich S. Tran, and Thomas Niederkrotenthaler. 2016. Relationship Satisfaction and Risk Factors for Suicide. Crisis 38: 7-16. [CrossRef] [PubMed]

Tong, Allison, Peter Sainsbury, and Jonathan Craig. 2007. Consolidated criteria for reporting qualitative research (COREQ): A 32-item checklist for interviews and focus groups. International Journal for Quality in Health Care 19: 349-57. [CrossRef] [PubMed]

Toomela, Aaro. 2005. Decision making with incomplete information: Systemic and nonsystemic ways of thinking in psychology and medicine. In Science and Medicine in Dialogue: Thinking through Particulars and Universalt. Edited by Bibace Roger. London: Praeger, pp. 231-41.

Van Heeringen, Cornelis, Gwendolyn Portzky, and Kurt Audenaert. 2004. The psychobiology of suicidal behavior. In Suicidal Behaviour: Theories and Research Findings. Edited by DeLeo Diego, Unni Bille-Brahe, Ad Kerkhof and Armin Schmidtke. Gottingen: Hogrefe \& Huber, pp. 61-66.

Värnik, Airi, Kairi Kõlves, Marika Väli, Liina-Mai Tooding, and Danuta Wasserman. 2007. Do alcohol restrictions reduce suicide mortality? Addiction 102: 251-56. [CrossRef] [PubMed]

Värnik, Airi, Merike Sisask, and Peeter Värnik. 2010. Baltic Suicide Paradox. Tallinn: Tallinn University Press / Tallinna Ülikooli Kirjastus.

Värnik, Peeter. 2012. Suicide in the World. International Journal of Environmental Research and Public Health 9: 760-71. [CrossRef] [PubMed]

Wasserman, Danuta. 2001a. A stress-vulnerability model and the development of the suicidal process. In Suicide: An Unnecessary Death. Edited by Wasserman Danuta. London: Martin Dunitz, pp. 13-27.

Wasserman, Danuta. 2001b. Affective disorders and suicide. In Suicide: An Unnecessary Death. Edited by Wasserman Danuta. London: Martin Dunitz, pp. 39-47.

Wasserman, Danuta. 2001c. Alcoholism, other psychoactive substance misuse and suicide. In Suicide: An Unnecessary Death. Edited by Wasserman Danuta. London: Martin Dunitz, pp. 49-57.

Wasserman, Danuta. 2016a. Negative life events and suicide. In Suicide: An Unnecessary Death. Oxford: Oxford University Press, pp. 136-144.

Wasserman, Danuta. 2016b. Suicidal people's experiences of trauma and negative life events. In Suicide: An Unnecessary Death. Oxford: Oxford University Press, pp. 145-150.

Wasserman, Danuta. 2016c. The suicidal process. In Suicide: An Unnecessary Death. Oxford: Oxford University Press, pp. 27-37.

World Health Organization. 2014. WHOI Preventing Suicide: A Global Imperative; Geneva: WHO. Available online: http:/ / www.who.int/mental_health/suicide-prevention/world_report_2014/en/ (accessed on 11 January 2018).

Wu, Andrew, Jing-Yu Wang, and Cun-Xian Jia. 2015. Religion and Completed Suicide: A Meta-Analysis. PLoS ONE 10: e0131715. [CrossRef] [PubMed]

Yuodelis-Flores, Christine, and Richard K. Ries. 2015. Addiction and suicide: A review. The American Journal on Addictions 24: 98-104. [CrossRef] [PubMed]

(C) 2018 by the authors. Licensee MDPI, Basel, Switzerland. This article is an open access article distributed under the terms and conditions of the Creative Commons Attribution (CC BY) license (http://creativecommons.org/licenses/by/4.0/). 